
УДК 616.8-005

DOI 10.11603/1811-2471.2019.v.i3.10442

\title{
ХРОНИЧЕСКИЕ ЦЕРЕБРОВАСКУЛЯРНЫЕ ЗАБОЛЕВАНИЯ, ОБУСЛОВЛЕННЫЕ АРТЕРИАЛЬНОЙ ГИПОТЕНЗИЕЙ, У ПАЦИЕНТОВ МОЛОДОГО ВОЗРАСТА
}

\author{
๑М. М. Мамурова, Ш. С. Олланова, А. А. Косимов, А. Т. Джурабекова \\ Самаркандский государственный медицинский институт, Самарканд, узбекистан
}

РЕзЮМЕ. В структуре цереброваскулярных заболеваний значительный вес имеют хронические формы сосудистых поражений головного мозга, которые в отечественной литературе традиционно трактуются как дисциркуляторная энцефалопатия (ДЭ). В последние годы цереброваскулярные расстройства имеют тенденцию к увеличению встречаемости среди лиц среднего и молодого возраста.

Цель - изучить клинико-неврологические особенности хронических цереброваскулярных заболеваний, обусловленных артериальной гипотензией (АГ), у пациентов молодого возраста.

Материалы и методы. Под наблюдением находилось 130 пациентов с АГ. Все пациенты прошли комплексное обследование (стандартное клиническое, включавшее сбор жалоб и анамнеза заболевания, описание объективного, неврологического статуса, биохимические, общий анализ крови и мочи, глюкоза крови, коагулограмма, липидограмма, креатинин, мочевина крови и др.), ЭКГ, УзИ сердца, суточный мониторинг АД, нейрофизиологические ЭЭГ).

Результаты. У больных С ДЭІ, обусловленной АГ, в Клинической картине вначале преобладали невротический и астенический синдромы, при ДЭ II - вестибулярный, цефалгический и когнитивных нарушений. Динамическое наблюдение показало усугубление цефалгического, вестибулярного, инсомнического синдромов и синдрома когнитивных нарушений и уменьшение астенического и цефалгического синдромов при длительности заболевания более 5 лет. Очаговые неврологические симптомы чаще были отмечены у больных с дэ II. Клинические синдромы были тесно связаны с характером суточного ритма АД. Так, вестибулярный синдром преобладал в III и IV группах больных, когнитивных нарушений - во II и IV, дискоординаторный и невротический во II, III и IV, астенический - в IV.

Выводы. Наши исследования освещают проблемы диагностики и лечения цереброваскулярной патологии у молодых пациентов, что чрезвычайно актуально, поскольку хронические расстройства развиваются постепенно, и пациенты часто обращаются за медицинской помощью в период, когда возможности лечения уже ограничены.

КЛЮчЕВЫЕ СЛОВА: хронические цереброваскулярные заболевания, артериальная гипотензия, дисциркуляторная энцефалопатия.

Вступление. Сосудистые заболевания головного мозга из-за высокой распространенности и тяжелых последствий для состояния здоровья населения представляют важнейшую медицинскую и социальную проблему [1-6].

В структуре цереброваскулярных заболеваний значительный вес имеют хронические формы сосудистых поражений головного мозга, которые в отечественной литературе традиционно трактуются как дисциркуляторная энцефалопатия (ДЭ) $[2,3]$.

Патогенез ДЭ обусловлен недостаточностью мозгового кровообращения в относительно стабильной форме или в виде повторных кратковременных эпизодов дисциркуляции, которые могут протекать бессимптомно или проявляться клинически. В условиях хронической гипоперфузии мозга механизмы компенсации истощаются, энергетическое обеспечение мозга становится недостаточным, в результате чего сначала развиваются функциональные расстройства, а затем и необратимые диффузные морфологические изменения мозга. Все это приводит к клиническим проявлениям хронической ишемии в виде субъективной и объективной симптоматики, возникающей из- за нарушения корково-стриарных и корковостволовых связей.

В настоящее время все больше внимания уделяется менее тяжелым формам когнитивной недостаточности (КН). Это отражает современную тенденцию к оптимизации максимально ранней диагностики и терапии когнитивной недостаточности $[3,6,7]$.

Хронические цереброваскулярные расстройства развиваются постепенно, и пациенты часто обращаются за медицинской помощью в период, когда возможности лечения уже ограничены. Диагностика на ранних стадиях существенно увеличивает шансы успешности профилактических и терапевтических мероприятий, что является социально важной задачей для профилактики ДЭ, инвалидизации населения, мозговых инсультов, сказывающейся на продолжительности и качестве жизни.

Несмотря на многочисленные исследования, проблема течения и исходов различных клинических вариантов хронической ишемии мозга не имеет однозначного решения, не существует единых критериев оценки состояния больных как в периоде клинической дестабилизации, так 
Огляди літератури, оригінальні дослідження, погляд на проблему, випадок з практики, короткі повідомлення

и на этапе реабилитации [1]. Имеется достаточное количество исследований, посвященных диагностике и лечению цереброваскулярной патологии у пациентов пожилого возраста, в то время как у молодых пациентов данная проблема освещена недостаточно.

Цель - изучить клинико-неврологические особенности хронических цереброваскулярных заболеваний, обусловленных АГ, у пациентов молодого возраста.

Материал и методы исследования. Под наблюдением находилось 130 пациентов с АГ (при АД ниже 100/60 мм рт. ст. в возрасте 25 лет и моложе, АД ниже 105/65 мм рт. ст. в возрасте старше 30 лет). Средний возраст больных составил $(34,2 \pm 0,65)$ года.

Все больные были разделены на две группы в зависимости от степени выраженности дисциркуляторной энцефалопатии (ДЭ І и ДЭ II). Среди больных с ЭАГ диагноз ДЭ І стадии был установлен у 47 (36,1%) человек, ДЭ ІІ стадии -у 83 (63,8 \%) человек. В обеих группах преобладали больные с ДЭ II стадии в возрасте 36-45 лет (59,3 и 50,5 \% соответственно). Наименьшее количество больных с дисциркуляторной энцефалопатией отмечено в обеих группах в возрасте 18-25 лет (9,6 и 12,5 \% соответственно). И если при ДЭ, обусловленной АГ, мужчин и женщин было практически поровну (51 и 49 \%), то в группе больных, где дэ была обусловлена ЭАГ, статистически достоверно $(\mathrm{P}<0,001)$ преобладали женщины (93,3 и 6,7%).

Все пациенты прошли комплексное обследование, при этом использовались следующие методы: стандартный клинический, включавший сбор жалоб и анамнеза заболевания, описание объективного неврологического статуса, биохимический (общий анализ крови и мочи, глюкоза крови, коагулограмма, липидограмма, креатинин, мочевина крови и др.), ЭКГ, УЗИ сердца, суточное мониторирование АД, нейрофизиологический - ЭЭГ.
Результаты и обсуждение. При анализе клинических данных у пациентов с АГ была диагностирована ДЭ І у 47 (36,1%) человек, ДЭ ІІ -у 83 $(63,8 \%)$ человек. У пациентов с ДЭ І, обусловленной АГ, отмечалась умеренно выраженная, локализованная в одной области головная боль, которая проявлялась при повышенной эмоциональной, умственной нагрузке или была связана с изменением метеорологических условий, проявляющаяся не чаще 1-2-х раз в неделю. Также периодически отмечались жалобы на головокружение, снижение концентрации внимания, утомляемость, снижение работоспособности.

У пациентов с ДЭ II, обусловленной АГ, головная боль отмечалась до 3-4-х раз в неделю, носила диффузный или пульсирующий характер, с локализацией в двух, трех областях головы. Часто головная боль сочеталась с головокружением, периодической шаткостью при ходьбе, снижением памяти на текущие события, затруднениями усвояемости нового материала. В большинстве случаев пациенты жаловались на снижение работоспособности, повышенную утомляемость, общую слабость, эмоциональную неустойчивость, расстройство сна. Особенностью общемозговых симптомов при ДЭ II было их наличие как при повышенном АД, так и при нормальных цифрах АД. Также при ДЭ II наблюдалось сочетание 2-3-х симптомов у одного больного. При анализе клинических жалоб у больных молодого возраста с ДЭ І и ДЭ ІІ, обусловленных АГ, были выделены основные клинические синдромы, которые представлены в таблице 1.

Из представленной таблицы видно, что клинические синдромы при АГ у пациентов молодого возраста на отдельных стадиях дЭ отмечаются неодинаково. У больных с ДЭ І преобладали следующие синдромы: астенический - у 27 (57,4ะ7,1 \%)

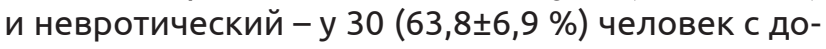
стоверностью $(\mathrm{P}=0,05)$. Сравнительно реже - дискоординаторный - у $10(21,3 \pm 5,4 \%)$, инсомничес-

Таблица 1. Клинические синдромы ДЭ І и ДЭ ІІ у больных АГ в молодом возрасте

\begin{tabular}{|c|c|c|c|c|}
\hline \multirow{2}{*}{ Синдромы } & \multicolumn{2}{|c|}{ ДЭ І, n=47 } & \multicolumn{2}{|c|}{ ДЭ ІІ, n=83 } \\
\hline & абс. число & $\% \pm m$ & абс. число & $\% \pm m$ \\
\hline Цефалгический & 26 & $55,3 \pm 7,1$ & 62 & $74,7 \pm 4,4^{*}$ \\
\hline Вестибулярный & 18 & $38,3 \pm 7,0$ & 69 & $83,1 \pm 4,1^{* * *}$ \\
\hline Когнитивных нарушений & 21 & $44,6 \pm 7,1$ & 59 & $71,0 \pm 5,5^{* *}$ \\
\hline Астенический & 27 & $57,4 \pm 7,1^{*}$ & 26 & $31,3 \pm 8,3$ \\
\hline Невротический & 30 & $63,8 \pm 6,9 *$ & 36 & $43,4 \pm 7,7$ \\
\hline Инсомнический & 16 & $34,0 \pm 6,8$ & 43 & $51,8 \pm 6,8^{*}$ \\
\hline Дискоординаторный & 10 & $21,3 \pm 5,4$ & 51 & $61,4 \pm 6,2 * * * *$ \\
\hline
\end{tabular}

Примечание. * $-\mathrm{P}=0,05, * *-\mathrm{P}=0,01, * * *-\mathrm{P}=0,001, * * * *-\mathrm{P}<0,001$. 
Огляди літератури, оригінальні дослідження, погляд на проблему, випадок з практики, короткі повідомлення кий - у $16(34,0 \pm 6,8 \%)$ и вестибулярный - у 18 $(38,3 \pm 7,0 \%)$ пациентов $(\mathrm{P}=0,01)$.

У больных с Дэ ІІ достоверно чаще отмечались следующие синдромы: цефалгический-у 62 $(74,7 \pm 4,4 \%)$, вестибулярный - у $69(83,1 \pm 4,1 \%)$, когнитивных нарушений - у $59(71,0 \pm 5,5 \%), и$ - $^{-}$ сомнический - у $43(51,8 \pm 6,8 \%)$, дискоординаторный - у $51(61,4 \pm 6,2 \%)$ пациента $(0,05=\mathrm{P}<0,01)$, что явилось следствием прогрессирования поражения головного мозга при ДЭ ІІ.

В результате обследования больных с АГ II степени были выделены четыре клинические группы в зависимости от выраженности суточного ритма АД в соответствии со степенью ночного

снижения АД: 1-ю клиническую группу составили 23 (27,7 \%) больных с нормальной (оптимальной) степенью ночного снижения АД «дипперы», 2-ю группу - 31 (37,3 \%) пациент с недостаточной степенью ночного снижения АД «нондипперы», 3-ю- 20 (24,1 \%) больных с повышенной степенью ночного снижения АД - «овердипперы», 4-ю - 9 (10,8 \%) человек с устойчивым повышением ночного АД - «найтпикеры». Проведена сравнительная характеристика клинических проявлений ДЭ у пациентов молодого возраста 1-4-й клинических групп в зависимости от показателей суточного ритма АД, представленная в таблице 2 .

Таблица 2. Клинические синдромы ДЭ у пациентов молодого возраста с АГ ІІ степени в зависимости от показателей суточного ритма АД

\begin{tabular}{|c|c|c|c|c|}
\hline Синдромы & $\begin{array}{c}\text { I группа } \\
\mathrm{n}=23 \text { a6c \% } \pm \mathrm{m}\end{array}$ & $\begin{array}{c}\text { II группа } \\
\mathrm{n}=31 \mathrm{a} 6 \mathrm{c} \% \pm m\end{array}$ & $\begin{array}{c}\text { III группа } \\
\mathrm{n}=20 \text { aбc \% } \pm \mathrm{m}\end{array}$ & $\begin{array}{c}\text { IV группа } \\
\text { n= } 9 \text { a6c \% } \pm m\end{array}$ \\
\hline Цефалгический & $1356,5 \pm 10,9$ & $2167,7 \pm 9,8$ & $1470,0 \pm 4,1$ & $777,7 \pm 15,1$ \\
\hline Вестибулярный & $1147,8 \pm 6,1$ & $1858,0 \pm 7,2$ & $1260,0 \pm 5,2 *$ & $888,8 \pm 13,2 * * *$ \\
\hline Когнитивных нарушений & $1252,2 \pm 7,4$ & $2270,9 \pm 7,0$ * & $1470,0 \pm 4,1$ & $888,8 \pm 13,2 * *$ \\
\hline Дискоординаторный & $834,7 \pm 8,5$ & $1961,3 \pm 9,1 * *$ & $1260,0 \pm 5,2^{*}$ & $777,7 \pm 15,1^{*}$ \\
\hline Астенический & $1356,5 \pm 10,9$ & $2477,4 \pm 8,7$ & $1470,0 \pm 4,1$ & $9100 \pm 2,6 * * *$ \\
\hline Невротический & $834,7 \pm 8,5$ & $1858,0 \pm 8,2^{*}$ & $1155,0 \pm 4,8^{*}$ & $777,7 \pm 15,1^{*}$ \\
\hline Инсомнический & $1043,5 \pm 10,9$ & $1238,7 \pm 9,5$ & $1050,0 \pm 12,1$ & $444,4 \pm 18,7$ \\
\hline
\end{tabular}

Примечание. * - P=0,05, ** - P<0,05, *** P=0,01 - достоверность различий данных I группы в сравнении с таковыми во II, III и IV группах.

Среди основных синдромов ДЭ, выявленных при обследовании пациентов, необходимо отметить вестибулярный - у $12(60,0 \pm 5,2 \%)$ человек III группы с достоверностью $(P=0,05)$ и у $8(88,8 \pm 13,2 \%)$ человек IV группы $(P=0,01)$. Синдром когнитивных нарушений выявлялся у $22(70,9 \pm 7,0 \%)$ больных во II группе $(\mathrm{P}=0,05)$ и у $8(88,8 \pm 13,2 \%)$ пациентов в IV клинической группе $(P<0,05)$. Дискоординаторный синдром был выявлен у 19 (61,3ะ9,1\%) больных $(P<0,05)$ во II, у $12(60,0 \pm 5,2 \%)$ больных в III группе $(P=0,05)$ и у $7(77,7 \pm 15,1 \%)$ человек в IV группе $(P=0,05)$. Невротический синдром отме- чался у пациентов II группы у $18(58,0 \pm 8,2 \%)$ больных и в III группе - у 11 (55,0 $\pm 4,8 \%)$ больных $(P=0,05)$, в IV группе - у $7(77,7 \pm 15,1 \%)$ человек $(\mathrm{P}=0,05)$. Астенический синдром наиболее выраженным был в IV группе пациентов $(P=0,01)$. Такие синдромы, как цефалгический и инсомнический, при сравнении в исследуемых клинических группах существенно не различались $(P>0,05)$.

При исследовании неврологического статуса у пациентов молодого возраста с ДЭ І и ДЭ II, обусловленной АГ, были выявлены очаговые неврологические симптомы, представленные в таблице 3.

Таблица 3. Очаговые неврологические симптомы у пациентов молодого возраста с ДЭ І и ДЭ ІІ, обусловленной АГ

\begin{tabular}{|c|c|c|c|c|}
\hline \multirow{2}{*}{ Очаговые симптомы } & \multicolumn{2}{|c|}{ ДЭ І ст., $\mathrm{n}=47$} & \multicolumn{2}{|c|}{ ДЭ ІІ ст., $\mathrm{n}=83$} \\
\hline & a6c. & $\% \pm m$ & a6c. & $\% \pm m$ \\
\hline Слабость конвергенции & 12 & $25,5 \pm 6,2$ & 33 & $39,8 \pm 4,9 *$ \\
\hline Надъядерный парез лицевого нерва & 3 & $6,38 \pm 3,4$ & 27 & $32,5 \pm 4,8 * *$ \\
\hline Парез подъязычного нерва & - & - & 31 & $37,3 \pm 4,9$ \\
\hline Равномерное оживление сухожильных рефлексов & 21 & $44,7 \pm 7,1$ & 37 & $44,6 \pm 5,0$ \\
\hline Ладонно-подбородочный рефлекс & - & - & 13 & $15,7 \pm 3,4$ \\
\hline Симптом Россолимо & 7 & $14,9 \pm 5,3$ & 24 & $28,9 \pm 4,6$ \\
\hline Интенционный тремор при пальце-носовой пробе & 6 & $12,8 \pm 5,0$ & 46 & $55,4 \pm 6,6 * *$ \\
\hline Неустойчивость в позе Ромберга & 4 & $8,5 \pm 3,9$ & 60 & $72,3 \pm 4,9 * *$ \\
\hline
\end{tabular}

Примечание. * - $\mathrm{P}=0,05, * *-\mathrm{P}<0,001$. 
Огляди літератури, оригінальні дослідження, погляд на проблему, випадок з практики, короткі повідомлення

Из данных таблицы видно, что у пациентов молодого возраста с ДЭ ІІ наиболее частыми, статистически достоверными очаговыми симптомами были слабость конвергенции, надъядерный парез лицевого нерва, интенционный тремор при пальце-носовой пробе и неустойчивость в позе Ромберга.

Выводы. У больных с ДЭ І, обусловленной АГ, в клинической картине вначале преобладали невротический и астенический синдромы, при дЭ II - вестибулярный, цефалгический и когнитивных нарушений. Динамическое наблюдение по- казало усугубление цефалгического, вестибулярного, инсомнического синдромов и синдрома когнитивных нарушений и уменьшение астенического и цефалгического синдромов при длительности заболевания более 5 лет. Очаговые неврологические симптомы чаще были отмечены у больных с ДЭ ІІ. Клинические синдромы были тесно связаны с характером суточного ритма АД. Так, вестибулярный синдром преобладал в III и IV группах больных, когнитивных нарушений - во II и IV, дискоординаторный и невротический - во II, III и IV, астенический - в IV.

\section{ЛИТЕРАТУРА}

1. Воробьева О. В. Эффективность винпотропила в терапии начальных проявлений цереброваскулярной патологии / О. В. Воробьева, Е. С. Тамарова // Журн. неврологии и психиатрии. - 2010. - № 9. - С. 39-42.

2. Захаров В. В. Умеренные когнитивные нарушения как мультидисциплинарная проблема / В. В. Захаров // Неврология, нейропсихиатрия, психосоматика. 2010. - № 2. - С. 5-10.

3. Катунина Е. А. Когнитивные нарушения при хронической недостаточности мозгового кровообращения / Е. А. Катунина // Consiliummedicum. - 2011. № 1. - С. 9-12.

4. Дамулин И. В. Легкие когнитивные нарушения /
И. В. Дамулин // Consiliummedicum. - 2011. - № 2. С. $138-141$.

5. Вознесенская Т. Г. Депрессия при цереброваскулярных заболеваниях / Т. Г. Вознесенская // Неврология, нейропсихиатрия, психосоматика. - 2009. - № 2. C. 9-12.

6. Kerola T. The complex interplay of cardiovascular system and cognition: How to predict dementia on the elderly? / T. Kerola, R. Kettunen, T. Nieminen // Int. J. Cardiol. 2010. - Vol. 12. - P. 19-23.

7. Sharp S. I. Hypertension is a potential risk factor for vascular dementia: systematic review / S. I. Sharp [et al.] // Int. J. Geriatr. Psychiatry. - 2010. - Vol. 12. - P. 29-32.

\section{REFERENCES}

1. Vorobyeva, O.V., \& Tamarova, E.S. (2010). Effektivnost vintropila $v$ terapii nachalnykh proyavleniy tserebrovaskulyarnoy patologii [Vinpotropil efficacy in therapy of primary signs of cerebrovascular pathology]. Zhurn. nevrologii i psikhiatrii - Journal of Neurology and Psychiatry, 110 (9), 39-42 [in Russian].

2. Zakharov, V.V. (2010). Umerennye kognitivnye narusheniya kak multidistsiplinarnaya problema [Light cognitive impairments as multidisciplinary problem]. Nevrologiya, neyropsikhiatriya, psikhosomatika-Neurology, Neuropsychiatry, Psychosomatics, (2), 5-10 [in Russian].

3. Katunina, E.A. (2011). Kognitivnye narusheniya pri khronicheskoy nedostatochnosti mozgovogo krovoobrashcheniya [Cognitive disorders in chronic cerebral circulation insufficiency]. Consilium Medicum, (1), 9-12 [in Russian].

4. Damulin, I.V. (2006). Legkie cognitivnye narusheniya
[Light cognitive disorders]. Consilium Medicum, 8 (8), 80-85 [in Russian].

5. Voznesenskaya, T.G. (2012). Depressiya pri tserebrovaskulyarnykh zabolevaniyakh [Depression in cerebral vascular diseases]. Nevrologiya, Neyropsikhiatriya, Psikhosomatika-Neurology, Neuropsychiatry, Psychosomatics, (2), 9-12 [in Russian].

6. Kerola, T., Kettunen, R., \& Nieminen, T. (2011). The complex interplay of cardiovascular system and cognition: how to predict dementia in the elderly? International Journal of Cardiology, 150 (2), 123-129.

7. Sharp, S. I., Aarsland, D., Day, S., Sonnesyn, H., Alzheimer's Society Vascular Dementia Systematic Review Group, \& Ballard, C. (2011). Hypertension is a potential risk factor for vascular dementia: systematic review. International Journal of Geriatric Psychiatry, 26 (7), 661-669. 


\author{
ОМ. М. Мамурова, Ш. С. Олланова, А. А. Косимов, А. Т. Джурабекова \\ Самаркандський державний медичний інститут, Самарканд, Узбекистан
}

РЕЗЮМЕ. У структурі цереброваскулярних захворювань значну питому вагу займають хронічні форми судинних уражень головного мозку, які традиційно трактуються як дисциркуляторна енцефалопатія (ДЕ). Останніми роками спостерігається тенденція до зростання цієї патології у осіб середнього та молодого віку.

Мета - дослідити клініко-неврологічні особливості хронічних цереброваскулярних захворювань, зумовлених артеріальною гіпотензією (АГ), у пацієнтів молодого віку.

Матеріали та методи. У дослідження включено 130 пацієнтів з АГ. Усі пройшли комплексне обстеження (стандартний клінічний огляд зі збором скарг та анамнезу, об'єктивного та неврологічного статусу, біохімічний та загальний аналіз крові та сечі, рівень глюкози крові, коагулограма, ліпідограма, креатинін, сечовина крові та інші), ЕКГ, УЗД серця, добовий моніторинг АТ, нейрофізіологічні ЕЕГ).

Результати. У хворих з ДЕ І, зумовленою АГ, переважали невротичний та астенічнй синдроми, при ДЕ II - вестибулярний, цефалгічний та когнітивних порушень. Динамічне спостереження показало посилення цефалгічного, вестибулярного, інсомнічного синдромів і синдрому когнітивных порушень та зменшення проявів астенічного та цефалгічного синдромів при тривалості хвороби більше 5 років. Вогнищеві неврологічні симптоми частіше спостерігалися у пацієнтів з ДЕ ІІ. Клінічні синдроми були тісно пов'язані з характером добового ритму АТ. Так, вестибулярний синдром переважав у III та IV групах хворих, когнітивні порушення - у II та IV, дискоординаційний та невротичний - у II, III та IV, астенічний - в IV.

Висновки. Наші дослідження висвітлюють проблеми діагностики та лікування цереброваскулярної патології у молодих паціентів, що надзвичайно важливо, оскільки патологія розвивається повільно і пацієнти часто звертаються за медичною допомогою у період, коли можливості лікування уже обмежені.

КлючОВІ СлОВА: хронічні цереброваскулярні хвороби, артеріальна гіпотензія, дисциркуляторна енцефалопатія.

\title{
CHRONIC CEREBROVASCULAR DISEASES CAUSED BY ARTERIAL HYPOTENSION IN YOUNG ADULTS
}

\author{
@M. M. Mamurova, Sh. S. Ollanova, A. A. Kosimov, A. T. Dzurabekova \\ Samarkand State Medical Institute, Samarkand, Uzbekistan
}

SUMMARY. In the structure of cerebrovascular diseases, chronic forms of vascular lesions of the brain, which are traditionally interpreted as dyscirculatory encephalopathy (DE), have significant weight in the domestic literature. In recent years cerebrovascular disorders have a tendency to increase the incidence among people of middle and young age.

The aim - to study the clinical and neurological parameters of chronic cerebrovascular diseases caused by arterial hypotension in young adults.

Materials and Methods. 130 young patients with arterial hypotension were involved. All patients were examined (standard clinical examination and anamnesis, neurological status, biochemical analysis of blood and urine, blood glucose, coagulogram, lipid profile, creatinine, blood urea etc.), ECG, heart ultrasound, arterial pressure daily monitoring, neurophysiological status, EEG.

Results and Discussion. In adults with DE of stage I, caused by arterial hypotension, neurotic and asthenic syndromes prevailed, stage II - vestibular, cephalgia and cognitive impairment observed. Dynamic observation for 5 years demonstrated aggravation of next syndromes namely vestibular, insomnia and cognitive impairments. Asthenia and cephalghia symptoms were reduced at the same time. Local neurologic symptoms were in DE stage II more frequently. All clinical symptoms had tight connection with the arterial pressure rhythm. Vestibular syndrome prevailed in clinical groups II and IV, dyscoordination and neurotic - in II, III and IV, asthenic in clinical group IV.

Conclusions. Our research involved problems of diagnosis and treatment of cerebrovascular pathology in young patients. It is a problem of high importance because of the pathology develops slowly and patients often seek medical care at times when treatment options are already limited.

KEY WORDS: chronic cerebrovascular diseases; arterial hypotension; dyscirculatory encephalopathy. 